\title{
Visceral control of drinking in rats
}

\author{
JAMES R. MARTIN \\ Institute for Behavioral Science, Swiss Federal Institute of Technology, Zürich, Switzerland
}

and

\author{
DONALD NOVIN \\ Department of Psychology and the Brain Research Institute \\ University of California, Los Angeles, California
}

\begin{abstract}
Hepatic-portal infusion of $.77 \mathrm{M} \mathrm{NaCl}(.5 \% \mathrm{BW})$ resulted in a shorter latency to drink than did jugular infusion for both sham-operated rats and rats subjected to abdominal vagotomy. However, .5-h water intake was not differentially affected by the route of hypertonic saline infusion in either group. Hepatic-portal infusion of an isotonic saline load resulted in greater water intake than did jugular infusion for both vagotomized and control rats, and the latency was shorter in vagotomized rats, but not in control animals, after hepatic-portal infusion than after a jugular infusion. Hypertonic saline was a more potent dipsogenic stimulus than isotonic saline for both routes of infusion, and vagotomy reduced water consumption produced by osmotic challenge. The results provide some evidence for a hepatic drinking system by demonstrating a differential effect of hepatic-portal and systemic saline infusions. However, this effect persists after abdominal vagotomy and possibly is mediated wholly, or in part, by other visceral innervation. In addition, abdominal vagotomy reduced water intake, but not latency to drink, induced with osmotic challenge given via either vascular route, an effect that may possibly be due to alterations in gastrointestinal function or to loss of afferent input from hypothetical visceral osmo- or sodium-sensitive cells that modulate drinking.
\end{abstract}

Recent experimental results have provided evidence that receptors located within the circulation of the liver detect perturbations in water and electrolyte balance and activate appropriate homeostatic mechanisms (Sawchenko \& Friedman, 1979). Electrophysiological investigations have provided evidence for the existence of osmo- or sodium-sensitive cells in several species (Adachi, Niijima, \& Jacobs, 1976; Andrews \& Orbach, 1974; Niijima, 1969). In addition, a number of studies have demonstrated the greater efficacy of hepatic-portal infusions of saline loads than of systemic infusions in eliciting physiological compensatory responses (Daly, Roe, \& Horrocks, 1967; Haberich, Aziz, \& Nowacki, 1965; Lydtin, 1969; Passo, Thornborough, \& Rothballer, 1973). However, relatively few investigations have considered the behavioral consequences of the activation of hepatic sodium- or osmo-sensitive mechanisms. Lin and Blake (1971) provided evidence that the liver contributes to the control of saline drinking preference behavior. It was demonstrated that only

This research was supported in part by Grant NS7687 from the National Institute of Neurological and Communicative Disorders and Stroke to D. Novin. J. R. Martin's present address is: Abteilung Pharmakologie, Experimentell-medizinische Forschung, E. Merck, Postfach 41 19, Frankfurter Strasse 250, 6100 Darmstadt 1, Bundesrepublik Deutschland. Requests for reprints should be sent to: Institut für Verhaltenswissenschaft, Sekretariat, ETH-Zürich, Turnerstrasse 1, Zürich CH-8092, Switzerland. hepatic-portal infusion of hypertonic saline decreased saline drinking, whereas infusion of hypertonic saline through the vena cava, as well as infusion of an equiosmotic sodium-free solution through either vein, failed to alter intake in a test of rats deprived of fluid for $24 \mathrm{~h}$ and then presented simultaneously with both water and saline. More recently, Blake and Lin (1978) demonstrated that, following right cervical vagotomy, hepatic-portal infusion of hypertonic saline no longer decreased saline drinking preference, although this denervation did not affect water or saline intake during control infusions or during a 24-h period of ad-lib food and water access.

Thus, there has accrued evidence for a hepatic mechanism that is sensitive to fluctuations in sodium concentration and, perhaps more generally, to changes in plasma osmolality, and that participates in the control of both physiological and behavioral responses regulating water and electrolyte balance. The present investigation focused on delineating the properties of the putative hepatic mechanism contributing to the control of water drinking and evaluated the importance of subdiaphragmatic vagal innervation in the mediation of this response. The relative effects of hepatic-portal and jugular infusions of hypertonic and isotonic saline on water intake were evaluated in both vagotomized and control rats. This bilateral vagotomy procedure, which included transection of the hepatic branch of the 
vagus, has previously been reported to abolish the satiating effects of hepatic-portal infusion of glucose (Novin, Sanderson, \& VanderWeele, 1974) and pancreatic glucagon (Martin, Novin, \& VanderWeele, 1978), possibly by interrupting fibers conveying information from putative hepatic glucoreceptors to the brain. More pertinently, bilateral subdiaphragmatic vagotomy has also been reported to disrupt osmotically induced drinking in rats (Kraly, Gibbs, \& Smith, 1975; Martin, 1981; Martin, Geiselman, \& Novin, 1979).

\section{METHOD}

\section{Animals}

The subjects were 50 male Long-Evans pigmented rats obtained from Simonsen Laboratories (Gilroy, California). Throughout the experiment, these rats received Purina lab chow and tap water ad lib except during the drinking tests when food was absent. Overhead fluorescent lights were set for a 12:12-h light-dark cycle, with light onset at $0830 \mathrm{~h}$.

\section{Surgery}

Prior to the denervation or control surgery, all rats were fasted for about $12 \mathrm{~h}$. The subjects were anesthetized with pentobarbital sodium $(50 \mathrm{mg} / \mathrm{kg} \mathrm{BW})$ and then subjected to either bilateral subdiaphragmatic vagotomy (Vagx), including transection of the hepatic branch of the anterior vagal trunk, or sham vagotomy (Sham) under antiseptic conditions. The details of these surgical procedures are provided elsewhere (Martin et al., 1979). During the subsequent 6-12-week recovery period, these rats were given palatable foods as a supplement to their regular laboratory diet in order to facilitate the maintenance of normal body weights.

After allowing sufficient time for the rats to recover from the trauma of the first surgical intervention (6-12 weeks), each rat underwent surgery a second time to receive a Silastic (Dow Corning: $.30 \mathrm{~mm}$ i.d. $\times .65 \mathrm{~mm}$ o.d.) cannula in either the hepatic-portal vein or the jugular vein. The cannula was inserted into a hepaticportal collecting vessel and threaded about $\mathbf{4 0} \mathrm{mm}$ through that vessel into the hepatic-portal vein. The jugular cannula was inserted into the jugular vein and threaded through this vessel to the vena cava. The cannulated veins were permanently ligated above the point of cannula entry, and blood was withdrawn to verify the intravenous placement of the cannula. The other end of the cannula proceeded through the wound and then subcutaneously to the head, where it was attached to a blunted 25-ga syringe needle. This needle was attached to four stainless steel screws fastened into the skull with dental acrylic cement. The cannula assembly was closed with the sealed tip of a Luer-Lok syringe. The rats received a $100,000-\mathrm{U}$ injection of penicillin after the completion of the surgery. During the subsequent recovery period of 4-7 days, the rats received palatable foods in addition to their regular diet. Each day, the cannulas were injected with heparinized physiological saline to maintain patency.

\section{Behavioral Testing}

Test infusions were done in the home cage according to a counterbalanced design during the last $6 \mathrm{~h}$ of the light portion of the day-night cycle. Each rat was infused twice with $.77 \mathrm{M} \mathrm{NaCl}$ and twice with $.15 \mathrm{M} \mathrm{NaCl}$, on separate days, at a rate of $.3 \mathrm{ml} / \mathrm{min}$. The infusion volume was . $5 \%$ of body weight. Immediately after the completion of an infusion, a bottle containing ambienttemperature water was attached to the cage. The bottles had spouts with ball bearings to minimize spillage and were weighed to the nearest $.1 \mathrm{~g}$ before and after the 30 -min period of water access. In addition, the latency to drink and the occurrence of drinking within each successive 1-min interval during the initial $15 \mathrm{~min}$ after infusion was recorded. The water-intake data were calculated on the basis of grams of water drunk per $100 \mathrm{~g}$ of body weight, and the values for the two tests at each concentration were averaged.

\section{Verification Procedures}

After the completion of all testing, the rats were anesthetized with pentobarbital sodium ( $50 \mathrm{mg} / \mathrm{kg} \mathrm{BW}$ ), and the completeness of vagal damage and the placement of the cannula was determined. The extent of vagal damage was assessed by electrically stimulating the cervical vagi while monitoring gastric contractions with a balloon inserted into the stomach and attached to a pressure transducer (Statham Laboratories). This procedure has been described in greater detail elsewhere (Martin, Rogers, Novin, \& VanderWeele, 1977). Vagally intact rats exhibited gastric contractions in response to the electrical stimulation, but those animals that had sustained extensive vagal denervation showed no evoked gastric contractions. Only the surgically vagotomized rats that failed to exhibit evoked contractions were included in the data analyses. All sham-operated rats exhibited evoked gastric contractions. It should be noted that the procedure used to verify vagal denervation assesses only efferent vagal function, but loss of afferent vagal function presumably occurs concomitant to the loss of efferent function following vagal transection. Furthermore, this test evaluates vagotomy-produced effects on gastric functioning, and from such gastric impairment it is inferred that the surgical denervation was extensive and extends to other vagally innervated organs and cells. After completion of the electrophysiological verification, the subjects were sacrificed with an overdose of pentobarbital sodium and the cannulas injected with dye during autopsy to demonstrate that the intravenous cannulas were functional and that their tips were in the appropriate location.

\section{Treatment of Date}

Water-intake data were analyzed with a factorial ANOVA to compare surgical condition (Vagx vs. Sham) and infusion route (jugular vs. hepatic-portal) for the isotonic condition and separately for the hypertonic-saline condition. Data concerning the number of rats drinking during the initial 3 min postinfusion were combined for the two surgical groups and compared for hepatic-portal and jugular conditions using the Mann-Whitney $\mathrm{U}$ test. Latency data were analyzed with either the Mann-Whitney $U$ test or the Wilcoxon matched-pairs signed ranks test. On the basis of the results of several previous investigations (Kraly et al., 1975; Lin \& Blake, 1971; Martin et al., 1979; Martin \& Novin, 1981), it was expected that Vagx rats would exhibit an attenuated drinking response to infusion of hypertonic saline and that infusion of hypertonic saline through the hepatic-portal vein would induce a stronger drinking response than would infusion through the jugular vein. All other $\mathrm{p}$ values were based upon nondirectional two-tailed analyses.

\section{RESULTS}

The data analyses were based upon 12 shamoperated rats with functional jugular cannulas, 13 sham-operated rats with functional hepatic-portal cannulas, 13 vagotomized rats with functional jugular cannulas, and 12 vagotomized rats with functional hepatic-portal cannulas. These 50 rats all met the appropriate verification criterion for vagal denervation (Vagx group) or absence of vagal damage (Sham group). Prior to surgery, the mean ( \pm SEM) body weights of these four groups were $253 \pm 17$, $226 \pm 12,263 \pm 20$, and $251 \pm 16 \mathrm{~g}$, respectively. At the time that behavioral testing began, the mean body weights of these groups were $362 \pm 16,331 \pm 13$, $347 \pm 18$, and $328 \pm 13 \mathrm{~g}$, respectively. 
Hypertonic saline infusion induced significantly greater water intake by Sham rats than by Vagx rats $[\mathrm{F}(1,46)=4.4, \mathrm{p}<.05]$, whereas there was no significant difference in water intake between Vagx and Sham groups following isotonic saline infusion across the two routes of administration. The latency to drink was significantly shorter after hepatic-portal infusion of hypertonic saline than after jugular infusion for both the Sham group (Mann-Whitney U test, $p<.05$ ) and the Vagx group (Mann-Whitney $U$ test, $\mathrm{p}<.001)$. However, there were no significant differences in the latencies between Vagx and Sham groups following either hypertonic or isotonic saline infusions given via the jugular or the hepatic-portal route. Hepatic-portal infusion of hypertonic saline produced only nonsignificantly greater water intake than did jugular infusion for both the Vagx and Sham groups. Hepatic-portal infusion of isotonic saline induced greater water intake than did jugular infusion for both the Vagx and Sham groups $[F(1,46)$ $=5.4, p<.05]$, although the magnitude of this differential effect of infusion route was quite small. Hepatic-portal infusion of isotonic saline also resulted in a shorter latency than did jugular infusion for Vagx rats (Mann-Whitney $U$ test, $p<.002$ ), but not for Sham rats. These latency and water-intake data are presented in Figures 1 and 2.

The number of rats drinking during each successive 1-min block for the initial $15 \mathrm{~min}$ of the test session was also examined, and the combined data for Vagx and Sham groups were compared across the two routes of administration. During the initial 3 min following infusion, a greater percentage of rats receiving portal infusion than rats receiving jugular infusion drank, in both the isotonic and the hypertonic saline infusion conditions ( $p s<.02)$. However, after about the 3rd min postinfusion, the

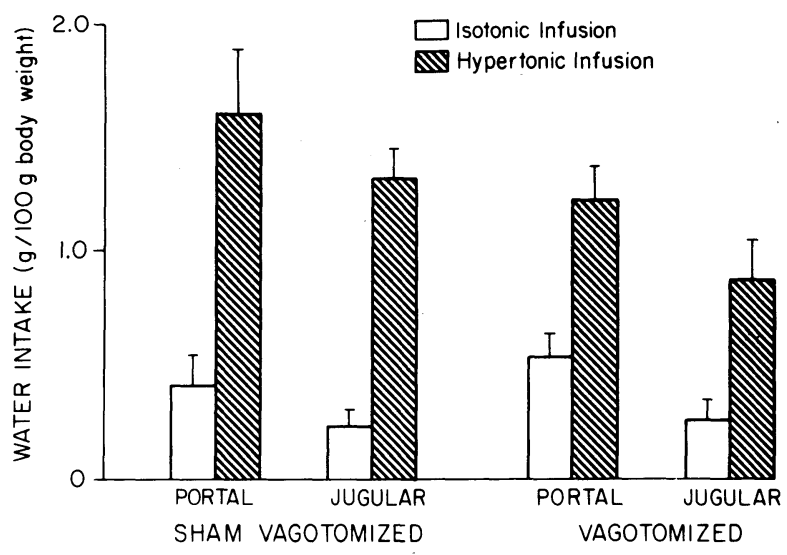

Figure 1. Water intake (mean \pm SEM) for vagotomized and sham-operated rats during the 30 -min period following infusion of different saline concentrations through either the hepatic-portal or the jugular vein.

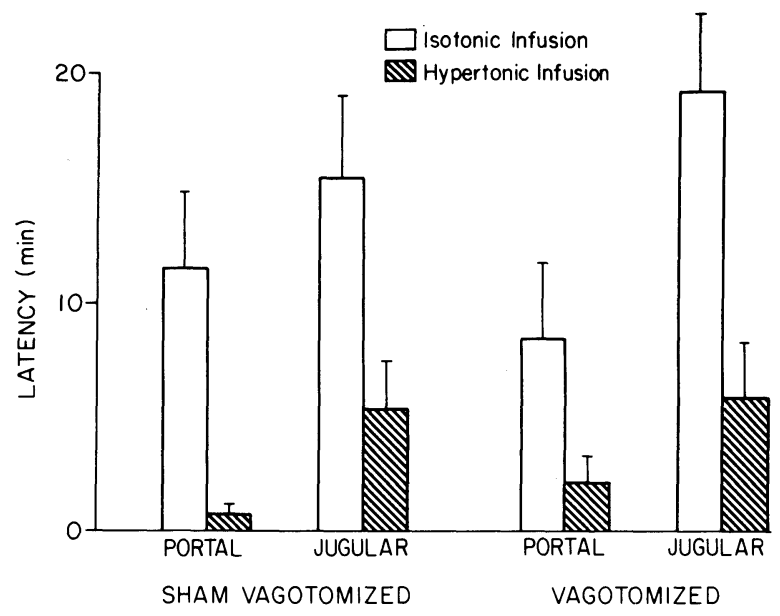

Figure 2. Latency to initiate drinking (mean time in minutes \pm SEM) for vagotomized and sham-operated rats following infusion of different saline concentrations through either the hepatic-portal or the jugular vein.

route of administration had no clear effect on the number of rats drinking.

\section{DISCUSSION}

The results of the present investigation provide additional evidence for the participation of a hepatic mechanism in the control of drinking in rats. It was demonstrated that hepatic-portal infusion of small volumes of $.77 \mathrm{M} \mathrm{NaCl}(.5 \% \mathrm{BW}, .3 \mathrm{ml} / \mathrm{min})$ in both Vagx and Sham rats resulted in significantly shorter latencies to initiate drinking than did comparable jugular infusions; however, .5-h water intakes in these two groups were not differentially affected by infusion route. Examination of the drinking patterns, calculated as the percentage of rats drinking in successive 1-min blocks, suggests that the differential effect of infusion route was pronounced only during the initial few minutes of access to water. Since both Vagx and Sham rats exhibited shorter latencies following hepatic-portal infusions of hypertonic saline than after jugular infusions, it seems unlikely that vagal innervation alone mediates this hepatic effect. Both Vagx and Sham rats exhibited slightly greater water intake following hepatic-portal infusion of isotonic saline in comparison with jugular infusion.

Lin and Blake (1971) have previously reported that water-deprived rats exhibited reduced saline preference following hepatic-portal infusion of hypertonic saline, but not of an equiosmotic sodium-free solution, or after caval infusion of either solution. It was subsequently noted that although hepaticportal infusion of hypertonic saline and glucose significantly altered saline drinking, hepatic-portal infusion of hypertonic sucrose or fructose, or caval infusion of any of these solutions, did not (Blake 
\& Lin, 1978). However, in contrast with the present experimental results, according to which abdominal vagotomy did not eliminate this differential effect of infusion route, Blake and Lin (1978) noted that unilateral right cervical vagotomy eliminated the differential effect on saline drinking preference produced by hepatic-portal vs. systemic infusions.

Evidence for the existence of hepatic osmo- or sodium-sensitive cells has been provided by electrophysiological studies. Schmitt (1973) demonstrated single neurons, located in the lateral hypothalamus, zona incerta, and ventral thalamus of the rat, that responded to portal, but not jugular, infusion of hypertonic saline. Rogers, Novin, and Butcher (1979) have reported that the central pathway for hepatic sodium-sensitive and osmosensitive cells parallels previously described gustatory afferents within the brain, as described by Norgren and Leonard (1973). Physiological evidence for hepatic osmoreceptors has been provided by Haberich et al. (1965), who demonstrated that hepatic-portal infusion of water resulted in a greater diuretic response than did a comparable infusion into the vena cava of rats. Subsequently, it was reported that when water was infused into the hepatic-portal vein and, simultaneously, $1.8 \% \mathrm{NaCl}$ (twice the isotonic concentration) of equal volume and rate was infused into the vena cava, pronounced diuresis resulted, whereas interchanging the infusion sites yielded transient antidiuresis (Haberich, Aziz, Nowacki, \& Ohm, 1969). The use of this simultaneous infusion technique confined the osmotic perturbations to the liver and its vasculature (and to a segment of the vena cava) and thereby precluded the activation of putative osmoreceptors located in the brain (Blass \& Epstein, 1971; Peck \& Novin, 1971; Verney, 1947; but also see Bie, 1980) or elsewhere in the viscera (Goldstein \& Halperin, 1977; Inchina \& Finkinshtein, 1964). However, although the data from several investigations have provided additional support for the finding that hepatic mechanisms influence fluid balance (Daly et al., 1967; Lydtin, 1969; Passo et al., 1973), other studies have produced conflicting results (Glasby \& Ramsay, 1974; Kapteina, Motz, Schwartz-Porsche, \& Gauer, 1978; Lindahl, Lund, Boas, \& Schmidt, 1974; Potkay \& Gilmore, 1970; Schneider, Davis, Robb, Baumber, Johnson, \& Wright, 1970).

The results of the present investigation also provide evidence for the existence of a visceral drinking mechanism mediated by vagal innervation consistent with earlier reports (Kraly et al., 1975; Martin \& Novin, 1981). It should be noted that the intravenous infusion of the osmotic load in the present study avoided possible differences in gut absorption of saline loads between vagotomized and control rats and minimized the stressfulness of the experimental procedure. Following abdominal vagotomy, intravenous infusion of hypertonic saline into either the hepatic-portal or the jugular vein produced significantly less water intake than that observed in control rats. However, vagotomy failed to significantly alter the latency, suggesting that perhaps this denervation produced the previously documented increased latency effect after intraperitoneal injection of a salt load (Kraly, 1978; Martin, 1981; Martin et al., 1979) by impairing absorption. Kraly (1978) has provided evidence that the attenuation of osmotically induced water intake after abdominal vagotomy results, at least in part, from alterations in gastric function. Blake and Lin (1978) reported that right cervical vagotomy abolished the inhibition of saline drinking by hepatic-portal infusion of hypertonic saline. In addition, other studies have demonstrated the importance of vagal innervation in mediating various physiological responses contributing to the control of electrolyte and water balance (Dennhardt, Ohm, \& Haberich, 1971; Passo et al., 1973). The failure of abdominal vagotomy to attenuate the differential effects of hepatic-portal and jugular infusions of saline in the present study indicates that the vagus alone probably does not mediate these effects, suggesting that perhaps other visceral innervation contributes to this differential effect of route of administration. However, it is difficult to determine the extent of the vagal denervation resulting from this surgical intervention, and, thus, the possible contribution of surviving vagal fibers cannot be excluded. In contrast, Blake and Lin (1978) reported that the greater dipsogenic effect of hepaticportal infusion of hypertonic saline in comparison with caval infusion was abolished by right cervical vagotomy. This apparent discrepancy may result from the different experimental procedures or perhaps from differences in the level and the extent of visceral denervation.

Although the hepatic branch of the vagus nerve in the rat has been reported to include an osmosensitive component (Niijima, 1969) and transection of the hepatic vagus has been reported to eliminate the hepatogenic diuresis induced by simultaneous infusion of water into the hepatic-portal vein and of $1.8 \% \mathrm{NaCl}$ into the vena cava (Dennhardt et al., 1971), this selective denervation did not abolish the greater urine flow and sodium excretion induced by hepatic-portal infusion of an isotonic saline load relative to caval infusion (Perlmutt, Aziz, \& Haberich, 1975). And hepatic vagotomy did not impair spontaneous drinking or responsiveness to osmotic and volemic regulatory challenges in rats (Martin, 1981). However, hepatic vagotomy did impair the capability of rats to alter urine concentration in response to hydration and dehydration (Adachi et al., 1976). These data suggest that the putative osmosensitive afferent fibers in the hepatic branch of the vagus nerve contribute, at best, only partially to behavioral regulation of water and electrolyte homeostasis. 
In sum, this investigation provides support for the existence of a hepatic mechanism in the rat that modulates the drinking response to both hypertonicsaline infusion (latency only) and isotonic-saline infusion (latency and water intake), although the differential drinking response for hepatic-portal vs. jugular routes produced by the isotonic-saline infusion condition was quite weak. This differential effect of infusion route was not blocked by bilateral subdiaphragmatic vagotomy that probably eliminated much of the vagal afferent and efferent innervation of the gut. Furthermore, the present results demonstrated that water intake elicited by intravenous infusion of hypertonic saline was considerably decreased by abdominal vagotomy.

\section{REFERENCES}

Adachi, A., Niıjima, A., \& Jacobs, H. L. An hepatic osmoreceptor mechanism in the rat: Electrophysiological and behavioral studies. American Journal of Physiology, 1976, 231, 1043-1049.

ANDREWs, W. H. H., \& OrBACH, J. Sodium receptors activating some nerves of perfused rabbit livers. American Journal of Physiology, 1974, 227, 1273-1275.

BIE, P. Osmoreceptors, vasopressin, and control of renal water excretion. Physiological Reviews, 1980, 60, 961-1048.

Blake, W. D., \& LiN, K. K. Hepatic portal vein infusion of glucose and sodium solutions on the control of saline drinking in the rat. Journal of Physiology (London), 1978, 274, 129-139.

Blass, E. M., \& Epste in, A. N. A lateral preoptic osmosensitive zone for thirst in the rat. Journal of Comparative and Physiological Psychology, 1971, 76, 378-394.

Daly, J. J., RoE, J. W., \& Horrocks, P. A comparison of sodium excretion following the infusion of saline into systemic and portal veins in the dog: Evidence for a hepatic role in the control of sodium excretion. Clinical Science, 1967, 33, 481-487.

Dennhardt, R., Оhm, W. W., \& Haberich, F. J. Die Ausschaltung der Leberäste des $\mathbf{N}$. vagus an der wachen Ratte und ihr Einfluss auf die hepatogene Diurese-indirekter Beweis für die afferente Leitung der Leber-Osmoreceptoren über den N. vagus. Pflügers Archiv, 1971, 328, 51-56.

GlasBy, M. A., \& RAmSAy, D. J. Hepatic osmoreceptors? Journal of Physiology (London), 1974, 243, 765-776.

Goldstein, D. J., \& Halperin, J. A. Mast cell histamine and cell dehydration thirst. Nature, 1977, 267, 250-252.

Haberich, F. J., Aziz, O., \& Nowacki, P. E. Ueber einen osmoreceptorisch tätigen Mechanismus in der Leber. Pflügers Archiv, 1965, 285, 73-89.

Haberich, F. J., Aziz, O., Nowacki, P. E., \& Оhм, W. Zur Spezifität der Osmoreceptoren in der Leber. Pflügers Archiv, $1969,313,289-299$.

Inchina, V. I., \& Finkinshtein, Y. D. Pancreatic osmo- and baroreceptors. Fiziologicheskii Zhurnal SSSR, 1964, 50, 301-305.

Kapteina, F. W., Motz, W., Schwartz-Porsche, D., \& Gauer, O. H. Comparison of renal response to $5 \%$ saline infusion into vena portae and vena cava in conscious dogs. Pflügers Archiv, 1978, 374, 23-29.

KRALY, F. S. Abdominal vagotomy inhibits osmotically induced drinking in the rat. Journal of Comparative and Physiological Psychology, 1978, 92, 999-1013.

Kraly, F. S., Gibbs, J., \& Smith, G. P. Disordered drinking after abdominal vagotomy in rats. Nature, 1975, 258, 226-228.

LIN, K. K., \& BlAKE, W. D. Hepatic sodium receptor in control of saline drinking behavior. Communications in Behavioral Biology, 1971, 5, 359-363.

Lindahl, F., Lund, B., Boas, B., \& Schmidt, A. Effect on the diuresis of simultaneously applied infusions of hypotonic liquid into the portal vein and of hypertonic liquid into the superior vena cava. Scandinavian Journal of Gastroenterology, 1974, 9, 133-136.

LyDTIN, H. Untersuchungen über Mechanismen der Osmo- und Volumen regulation II. Untersuchungen über den Einfluss intravenös intraportal und oral zugeführter hypotoner Kochsalzlösung auf die Diurese des Hundes. Zeitschrift für die Gesamte Experimentelle Medizin, 1969, 149, 193-210.

Martin, J. R. Effects of partial and complete vagal denervation on spontaneous ingestion and drinking induced with volemic and osmotic regulatory challenges. Journal of Neuroscience Research, 1981, 6, 243-250.

Martin, J. R., Geiselman, P. J., \& Novin, D. Drinking to intracellular dehydration following vagotomy in rats. Physiology \& Behavior, 1979, 23, 527-537.

Martin, J. R., \& Novin, D. Response to dipsogenic stimuli after abdominal vagotomy in rats. Physiological Psychology, $1981,9,181-186$.

Martin, J. R., Novin, D., \& VanderWeele, D. A. Loss of glucagon suppression of feeding after vagotomy in rats. American Journal of Physiology, 1978, 234, E314-E318.

Martin, J. R., Rogers, R. C., Novin, D., \& VanderWeele, D. A. Excessive gastric retention by vagotomized rats and rabbits given a solid diet. Bulletin of the Psychonomic Society, 1977, 10, 291-294.

Ninjima, A. Afferent discharges from osmoreceptors in the liver of the guinea pig. Science, 1969, 166, 1519-1520.

Norgren, R., \& Leonard, C. M. Ascending central gustatory pathways. Journal of Comparative Neurology, 1973, 150, 217-238.

Novin, D., Sanderson, J. D., \& VanderWeele, D. A. The effect of isotonic glucose on eating as a function of feeding condition and infusion site. Physiology \& Behavior, 1974, 13, 3-7.

Passo, S. S., Thornborough, J. R., \& Rothballer, A. B. Hepatic receptors in control of sodium excretion in anesthetized cats. American Journal of Physiology, 1973, 224, 373-375.

PECK, J. W., \& Novin, D. Evidence that osmoreceptors mediating drinking in rabbits are in the lateral preoptic area. Journal of Comparative and Physiological Psychology, 1971, 74, 134-147.

Perlmutt, J. H., Aziz, O., \& Haberich, F. J. A comparison of sodium excretion in response to infusion of isotonic saline into the vena porta and vena cava of conscious rats. Pflügers Archiv, 1975, 357, 1-14.

Potkay, S., \& Gilmore, J. P. Renal responses to vena caval and portal venous infusion of sodium chloride in unanaesthetized dogs. Clinical Science, 1970, 39, 13-20.

Rogers, R. C., Novin, D., \& Butcher, L. L. Hepatic sodium and osmoreceptors activate neurons in the ventrobasal thalamus. Brain Research, 1979, 168, 398-403.

Sawchenko, P. E., \& Friedman, M. I. Sensory functions of the liver-A review. American Journal of Physiology, 1979, 236, R5-R20.

SchмiтT, M. Influences of hepatic portal receptors on hypothalamic feeding and satiety centers. American Journal of Physiology, 1973, 225, 1089-1095.

Schneider, E. G., Davis, J. O., Robb, C. A., Baumber, J. S., Johnson, J. A., \& Wright, F. S. Lack of evidence for a hepatic osmoreceptor mechanism in conscious dogs. American Journal of Physiology, 1970, 218, 42-45.

VERNEY, E. B. The antidiuretic hormone and factors which determine its release. Proceedings of the Royal Society of London (Series B), 1947, 135, 25-106.

(Manuscript received February 1, 1982; revision accepted for publication September 7,1982 .) 